\title{
A Rare Case of Ureteroileal Fistula from Indian Tertiary Care Center
}

\author{
Vijay Sharma ${ }^{1}$, Pankaj Verma ${ }^{2}$, Manish Gupta ${ }^{3}$, Dinesh Gupta ${ }^{4}$ and Richa Sharma ${ }^{5 *}$ \\ ${ }^{1}$ Department of Gastroenterology, Manipal Hospital, India \\ ${ }^{2}$ Department of Radiology, Manipal Hospitals, India \\ ${ }^{3}$ Department of Urology, Manipal Hospital, India \\ ${ }^{4}$ Department of Oncosurgery, Manipal Hospital, India \\ ${ }^{5}$ Department of Community Medicine, Regional Institute of health, India
}

Submission: May 21, 2018; Published: July 02, 2018

"Corresponding author: Richa Sharma, Department of Community Medicine, Regional Institute of Health, Medicine, Research, 170B, Indira Colony, Bani Park, Jaipur, India, Email: drrichas@gmail.com

\section{Mini Review}

A sixteen-year-old girl reported to department of Gastroenterology, Manipal Hospital, Jaipur with history of chronic diarrhoea, this diarrhoea was there for 3 months, with watery stool, diarrhoea having no relation to food intake, times of the day, not relieving with any medicine tried, patient seen my many gastroenterologists earlier normal duodenoscopy and full colonoscopy, no ileoscopy done. There was history of laparoscopic cholecystectomy a few months back for symptomatic gall stones for which she was operated, postsurgery one week was uneventful, then she developed diarrhoea, diagnosis was kept as bile acid diarrhoea treated conservatively and family reassured for gradual recovery, but diarrhoea did not improve, bile acid binding agent did not work, course of anthelminthic, antidiarrheal, modified diet did not work, there was no weight loss, family was distressed, met me at OPD parents and the girl all were weeping as she was troubled due to watery diarrhoea day and night, unable to sleep. Two points she told after detailed discussion that after more water intake diarrhea worsens and before motion, she felt pain in the right iliac fossa. As we suspected some kind of spurious diarrhea due to surgical complication and communication of intestine and ureter, we sent stool sample of the patient for urea creatinine measurement, stool creatinine was $30 \mathrm{mg} / \mathrm{dl}$ and stool urea was $700 \mathrm{mg} / \mathrm{dl}$. It supported the diagnosis of spurious diarrhea (urine coming from bowel as the watery stool). The patient underwent contrastenhanced Compound tomography of the abdomen, it revealed communication of ileum lower end with right ureter lower one third. Now diagnosis of Ureteroileal fistula was confirmed [15]. The patient was referred to the Urologist, she underwent cystoscopy, urinary bladder was normal, right ureteric stent was placed, Foleys catheter placed to decrease pressure in bladder for one month, diarrhoea stopped, patient improved, later on, follow up after removal of Foleys catheter she was doing fine and she was satisfied with the treatment (Figure 1) [5,6].

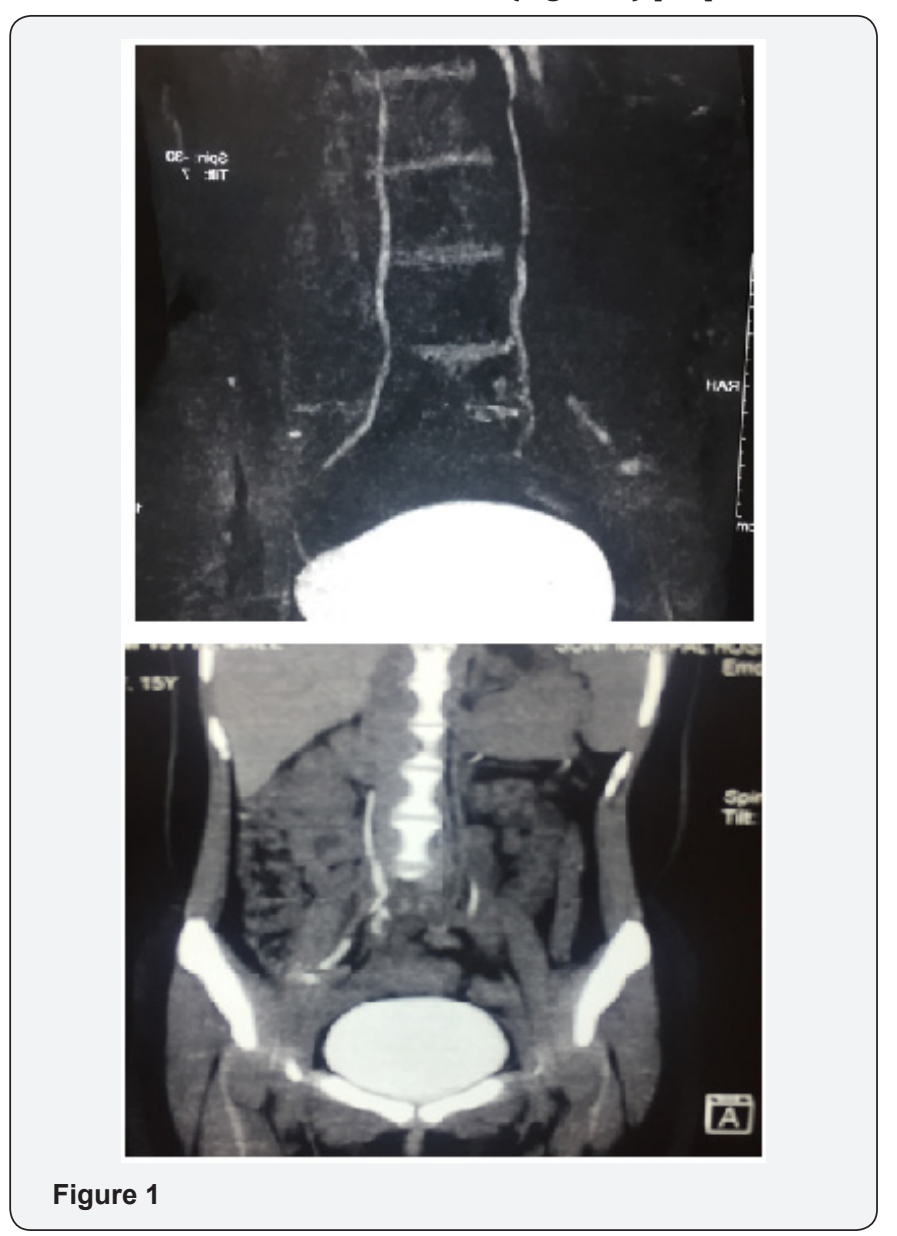




\section{Discussion}

Fistula's which communicate between the Urinary system and intestine are rare, and among them, fistulas that involve the urinary and intestinal tracts means vesicointestinal fistulas are the most common, Vesicoureteric fistulas are caused by diverticulitis, carcinoma colon [7]. Ureterocolonic fistulas are caused by the inflammatory condition of the urinary system or colon like an untreated perinephric abscess, calculus pyonephrosis. An intestinovesical fistula is of five types which include congenital, traumatic, inflammatory, neoplastic and foreign body, the same classification is useful for ureteroileal fistula. One series of thirteen cases of urointestinal fistula, not a single case had a ureteroileal fistula. One case report of tubercular ureteritis, pyelitis and pyelonephritis had a ureteroileal fistula [8]. Post radiotherapy of carcinoma uterus and carcinoma cervix many patients developed ureteroileal fistula; one case report of perforating abdominal trauma with chronic chloride resorption from ileum have been reported. While nephrointestinal fistulas are infrequent and Ureteroileal fistulas are extremely rare, with only six previously reported cases by another group. A review of the literature shows that involvement of the ureter secondary to inflammatory bowel disease is rare, never reported with ulcerative colitis, there are reports of few patients developing Ureteroileal fistulas due to Crohn's disease. One old case series reported three patients, who developed the ureteroileal fistula postoperatively, including one after radical pelvic surgery for advanced ovarian carcinoma, one following failed transureteroureterostomy and one after a repeat left ureteral reimplant with a pelvic abscess. Infection and/or urinary leakage had a major role in these cases, like other previously reported fistulas. Most of the earlier reported patients underwent surgical excision or revision; many patients were managed successfully with percutaneous nephrostomy or indwelling ureteral stents [9-11]. Crohn's disease patients are managed with Infliximab with or without ureteric stenting and bladder catheterization. There are a few case reports of the Ureteroileal fistula with diverticulitis, many of these cases are managed by diverting sigmoid colectomy, colostomy with ureteric stenting; later retrograde pyelogram was done to document healing of fistula and anastomosis of colon done after resection of diverticulitis.
Now a day most of the cases are managed by conservative treatment; by successful conservative management today we can bypass operative intervention in these rare fistulas. Surgeons should be especially careful while operating close to the ureter.

\section{Conclusion}

It was a very rare case of Ureteroileal fistula post laparoscopic surgery trauma, which presented with chronic spurious diarrhea, managed conservatively with ureteric stenting and Foley's catheterization.

\section{References}

1. Samuel L, Flaster, Irving, M Bush (1973) Ureteroileal Fistula: Report of a Case Complicated by Increased Chloride Reabsorption from the Ileal Segment. The Journal of Urology 104(4): 589- 591.

2. Nieh PT (1983) Ureteroileal Fistulas October. The Journal of Urology 130(3): 555-557.

3. Suhler A, Garbit JL, Blitz M (1995) Ureteroileal fistulas. Ann Urol (Paris) 29(1): 15-17.

4. Valerio S, Fornasiero G, Antoniazzi G, Bassi E (1992) Ureterocolic fistula: a case report. Arch Esp Urol 45(1): 95-96.

5. Maeda Y, Nakashima S, Misaki T (1998) Ureterocolic fistula secondary to colonic diverticulitis. Int J Urol 5(6): 610-6122.

6. Krishna AV, Dhar N, Pletman RJ, Hernandez I (1977) Spontaneous closure of ureterocolic fistula secondary to diverticulitis. J Urol 118(3): 476-477.

7. Ajit P, Jasna Cc, John J (2014) Spontaneous ureterocolic fistula secondary to diverticulitis: report of a case and review of literature. International Journal of Colorectal Disease 29(3): 417.

8. Osawa G, Tanaka Y, Andoh H, Yoshimatsu K, Ogawa K (2007) Ureterocolic fistula secondary to colonic diverticulitis. Int J Urol 32: 52-54.

9. Klarenbeek BR, De Korte N, Van der Peet DL, Cuesta MA (2012) Review of current classifications for diverticular disease and a translation into clinical practice. Int J Colorectal Dis 27(2): 207-214.

10. Humes DJ, West J (2012) Role of acute diverticulitis in the development of complicated colonic diverticular disease and 1-year mortality after diagnosis in the UK: a population-based cohort study. Gut 61(1): 95100 .

11. Krishna AV, Dhar N, Pletman RJ, Hernandez I (1977) Spontaneous closure of ureterocolic fistula secondary to diverticulitis. J Urol 118(3): 476-477. 
This work is licensed under Creative Commons Attribution 4.0 License DOI: 10.19080/ARGH.2018.10.555776

\section{Your next submission with JuniperPublishers} will reach you the below assets

- Quality Editorial service

- Swift Peer Review

- Reprints availability

- E-prints Service

- Manuscript Podcast for convenient understanding

- Global attainment for your research

- Manuscript accessibility in different formats

( Pdf, E-pub, Full Text, audio)

- Unceasing customer service

Track the below URL for one-step submission https://juniperpublishers.com/online-submission.php 